\title{
Evaluation of HARMONIE in the KNMI Parameterisation Testbed
}

\author{
E. I. F. de Bruijn and W. C. de Rooy \\ Royal Netherlands Meteorological Institute, De Bilt, The Netherlands \\ Correspondence to: E. I. F. de Bruijn (cisco.de.bruijn@knmi.nl)
}

Received: 14 January 2012 - Revised: 20 June 2012 - Accepted: 25 June 2012 - Published: 9 August 2012

\begin{abstract}
HARMONIE, a non-hydrostatic NWP model has a single column version which is used for testing and validation of physical parameterisations. Since January 2010, this single column model (SCM) has been run on a daily basis in the KNMI parameterisation testbed (KPT). In this testbed, the HARMONIE SCM is run with different options and the output is compared with a wide variety of observations and other participating SCMs as well as large-eddy simulations (LES) model output. The evaluation presented here makes use of the advanced observation site Cabauw in the Netherlands, with a focus on shallow convection, turbulence and cloud formation. The examples shown illustrate the potential of the daily monitoring and in-depth evaluation to detect and improve model deficiencies.
\end{abstract}

\section{Introduction}

HARMONIE is a non-hydrostatic NWP model that is used for mesoscale predictions. It is developed in cooperation with the HIRLAM and ALADIN consortia. In this paper we focus on HARMONIE cycle 36 with AROME physics (Seity et al., 2012). Due to the high horizontal resolution of $2.5 \times 2.5 \mathrm{~km}^{2}$, we assume that deep convection is resolved, while shallow convection still needs to be parameterised. For the validation of the physical parameterisations, a single column version of HARMONIE is available. Since January 2010, this single column model (SCM) is run on a daily basis in the KNMI parameterisation testbed (KPT) (see Neggers et al., 2012 and Sect. 2.1). In this testbed the HARMONIE SCM is validated against observations and large- eddy simulations (LES) (see Heus et al., 2012 and Sect. 2.2). The output can also be compared with other SCM's, extracted from different NWP models participating in the KPT. The KPT is suitable and has been successfully used for evaluating model performances for fast processes, such as shallow convection, turbulence and surface processes. As a result, several deficiencies in the model's physical parameterisations have been found and improved. The aim of this article is to illustrate the potential of the daily monitoring in the KPT by showing an evaluation of the HARMONIE SCM focusing on low clouds and mist. This is done by showing two examples in which striking differences occur between two HARMONIE model configurations with different convection and cloud schemes. Observations from Cabauw and LES output are used as reference.

\section{Set-up of the system}

\subsection{The parameterisation testbed}

In the KPT, a so-called host model provides data for running a SCM, because time and height dependent geostrophic wind speed and advection fields of temperature, humidity are needed. The driver files, containing this information, are derived from the most recent regional atmospheric climate model (RACMO) (van Meijgaard et al., 2008) forecast. RACMO has a resolution of 0.2 degrees and is initialized with the ECMWF analysis and forced by boundaries from the same model. During the complete $72 \mathrm{~h}$ forecast, the SCM output is nudged to the RACMO state with a relaxation time of $6 \mathrm{~h}$ to prevent it from drifting away. As a result the SCM is still able to develop short living features like clouds, but will also stay close to the background model RACMO on longer timescales. 

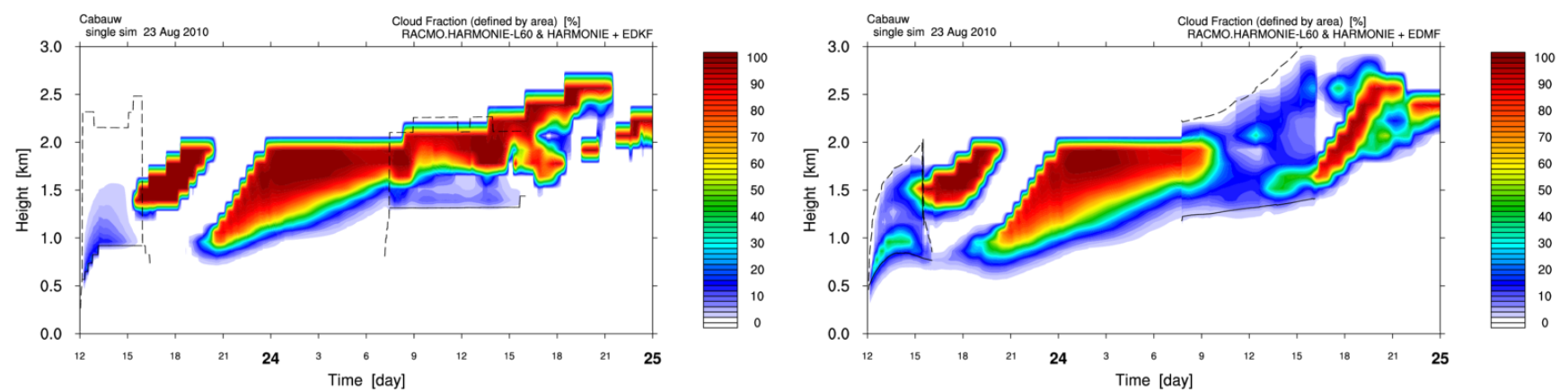

Figure 1. Cloud fraction of EDKF (left), EDMF (right) for 24 August 2010 (analysis 23 August 2010, 12:00 UTC) . The solid line is lifting condensation level and dashed line is the updraft termination height.

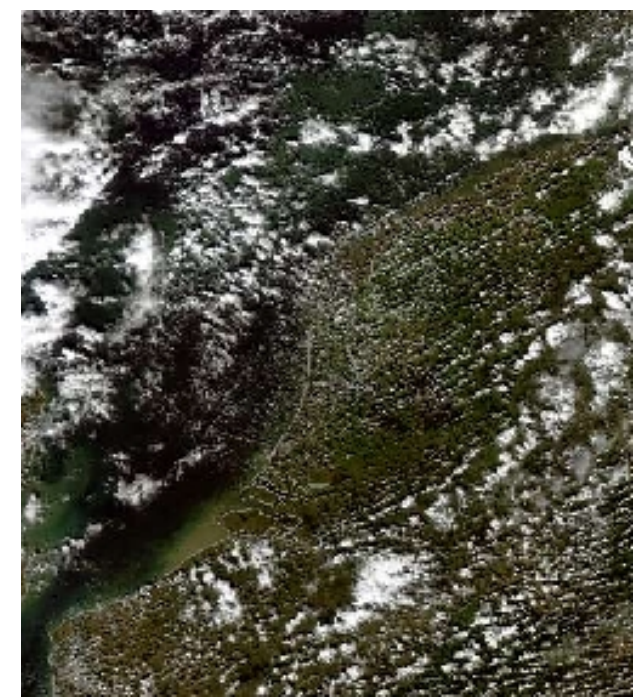

Figure 2. MODIS VIS satellite picture on 24 August 2010, 12:21 UTC.

\subsection{Observations and LES}

For evaluation we use observations and LES. The Cabauw site in the Netherlands offers a wide variety of quality observations. These observations comprise a $200 \mathrm{~m}$ tall tower with sensors for temperature, humidity and wind components and ground-based remote sensing instruments like lidar and cloud radar. Also LES output is used for validation. LES with its very high resolution $\left(100 \times 100 \mathrm{~m}^{2}\right)$ in the horizontal and $40 \mathrm{~m}$ in the vertical are well capable of resolving convection and for convective situations they can be considered as pseudo observations (see e.g. Siebesma and Cuijpers, 1995). LES produce additional information of the atmospheric state which the instrumentation does not provide, for instance the vertical profiles of cloud cover and mass flux.

\subsection{Convection schemes}

In this study we focus on the validation of two alternative mass flux shallow convection schemes. The Eddy Diffusivity Kain Fritsch (EDKF) scheme (Pergaud et al., 2009) represents convection with one updraft and lateral mixing between this updraft and the environment is described according to Kain and Fritsch (1990). The alternative convection scheme, noted here as the EDMF scheme uses a dry and wet updraft (Neggers et al., 2009) and lateral mixing is described according to de Rooy and Siebesma (2008). As discussed in de Rooy et al. (2012), it can be expected that the lateral mixing is better represented, i.e. in better correspondence with LES in the EDMF scheme than in the EDKF scheme. Consequently, e.g. the mass flux profile and cloud top height should be estimated more accurately with the EDMF scheme.

\subsection{Cloud schemes}

The EDKF scheme is combined with a statistical cloud scheme in which variance of the moisture deficit is produced by turbulence only. In addition to the cloud cover resulting from this statistical cloud scheme, an extra term proportional to the updraft fraction from the convection scheme is added. The EDMF scheme uses a full statistical cloud scheme with a variance of the moisture deficit produced by turbulence and convection. Apart from turbulence and convection there can be other sources of variance like gravity waves and mesoscale organization. To account for this, the EDMF scheme applies an additional variance term proportional to the saturation total water specific humidity. As explained in de Rooy et al. (2010), in this way we add the characteristics of a RH-scheme, where cloud cover is simply a function of the relative humidity to a statistical cloud scheme.

\section{Results}

Figure 1 presents the development of the cloud cover during 24 August 2010, based upon an analysis on $23 \mathrm{Au}-$ gust, 12:00 UTC. In EDKF (left) there is no break-up of the stratocumulus cloud deck, whereas in EDMF the cloud 

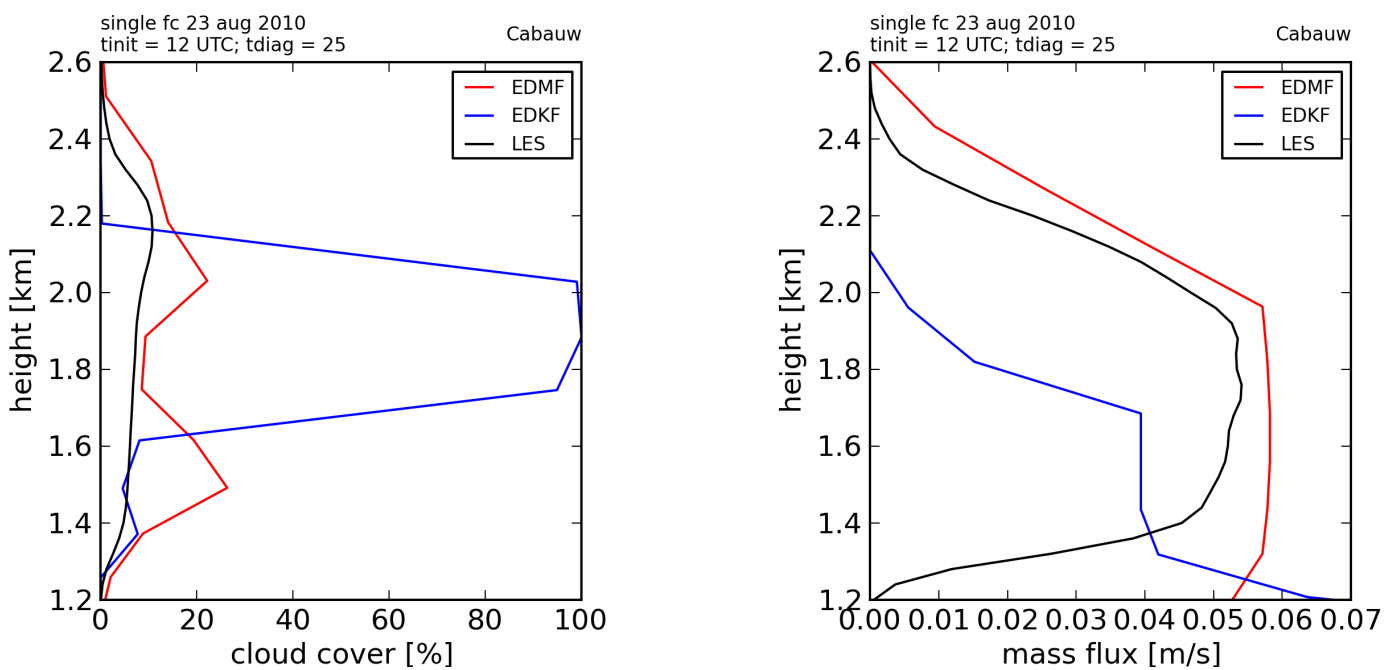

Figure 3. Profiles of cloud fraction (right) and mass flux (left) at $t=+25 \mathrm{~h}$, validation time for 24 August 2010, 13:00 UTC. Note that the cloud base height is at approximately $1.4 \mathrm{~km}$.
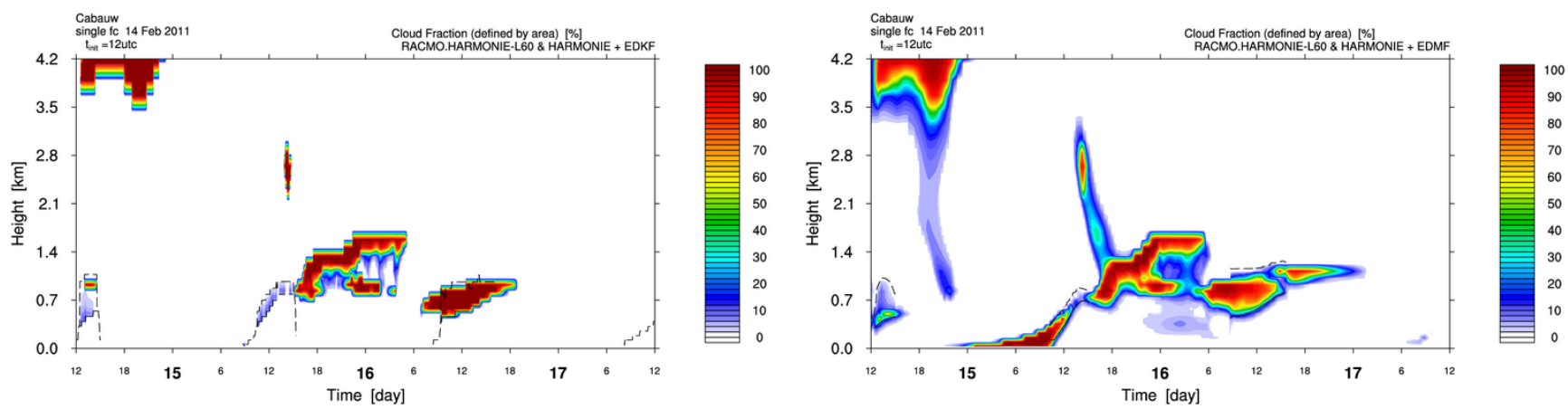

Figure 4. Cloud fraction represented by EDKF (left) and EDMF (right) for 15 February 2011. Note the development of fog during the night with EDMF.

fraction is becoming less after $25 \mathrm{~h}$ of forecast time. The cloud base and top are represented by the lifting condensation level (solid line) and updraft termination height (dashed line). These variables are only present when the convection scheme is active. In EDMF, the updraft termination height increases as soon as the cloud deck breaks up. In reality the stratocumulus deck did break up as illustrated by a satellite picture of the Netherlands (see Fig. 2) and the cloud fraction according to LES (see Fig. 3 left panel). Figure 3 reveals the good correspondence of the cloud cover profile of LES and EDMF in contrast with the large overcast with EDKF. If we take a look at the corresponding mass flux profile for this hour (Fig. 3 right panel), we see that the EDKF scheme deposits the moisture in too shallow layer, whereas the EDMF mass flux profile shows a much better correspondence with LES. As a result the EDKF scheme produces a persistent, not observed stratocumulus layer. Due to a better representation of lateral mixing, EDMF shows a better correspondence to the LES mass flux profile as could be expected based on de Rooy et al. (2012). However, the too low cloud top height in
EDKF might also be affected by the missing of the release of energy due to coagulation. As a result of this, the updraft in EDKF does not gain buoyancy from the coagulation process and terminates at a too low level.

During the second case of 15 February 2011, radiation fog was developed in Cabauw. At 00:00 UTC, the reported $10 \mathrm{~m}$ windspeed was $1 \mathrm{~m} \mathrm{~s}^{-1}$ and the fog layer had a vertical extent of $400 \mathrm{~m}$. The fog layer slightly increased and started to disappear after 04:00 UTC. The EDKF parameterisation was not able to capture the fog (Fig. 4) while EDMF with a modified cloud scheme was able to give some fog warning. The synoptical observations (Fig. 5) gave a reduced visibility of less than $200 \mathrm{~m}$ during the morning hours and back scatter observations from a Lidar device (not shown) in Cabauw confirmed the presence of very low clouds. The improved fog forecast is related to the modification in the statistical cloud scheme. Note that the convection scheme is not active under these stable conditions. In typical fog conditions there is no convection and limited turbulence. Consequently, the variance of the moisture deficit used in the statistical cloud 


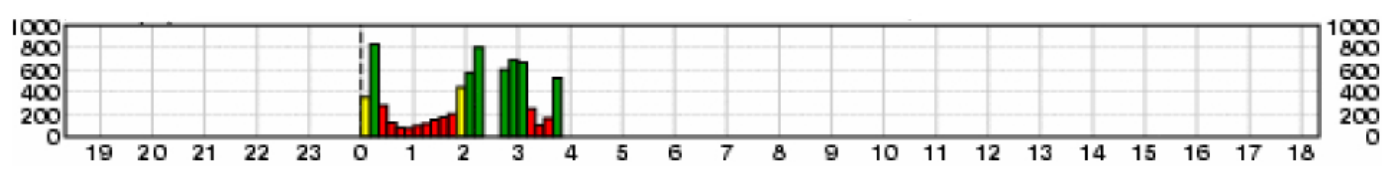

Figure 5. Synoptical visibility observations in [m] in Cabauw during 14-15 February 2011.

scheme can be extremely low. As a result no fog might be produced despite the small moisture deficit. The extra variance term in the EDMF cloud scheme helps to produce fog in these kind of conditions. It should be noted that the fog disappeared in the course of the morning, whereas the EDMF parameterisation was too late in predicting the vanishing of the fog.

\section{Conclusions and discussion}

Single column models and the KNMI parameterisation testbed have been shown to be useful tools for model evaluation of fast local processes like turbulence and convection. Based on daily monitoring and an in-depth validation against different observations, several deficiencies could be linked to particular physical processes captured inadequately by the corresponding parameterisations. The cases presented here do not stand alone but illustrate typical behavior of the EDKF and EDMF convection and cloud scheme in certain conditions. For example with the EDKF option, the convective transport is often too shallow which results in an accumulation of moisture in a too shallow layer and accordingly a too persistent stratocumulus cloud deck.

Another example deals with insufficient production of variance of moisture deficit in certain circumstances like fog. The modification of the statistical cloud scheme of EDMF turned out to be crucial to capture many observed fog cases. However, in this particular case the simulated fog is too persistent.

The SCM approach has also drawbacks. Due to the coarse prescribed dynamical tendencies, mesoscale circulations can not be captured adequately. The data to force the model should be accurate and preferably not derived from a foreign host model to circumvent the mismatch between the physical parameterisations. Therefore, it is recommended to make tendencies from the 3-D HARMONIE model available for running the SCMs. In a new cycle of HARMONIE planned for 2012, there is an option of extracting fields from the 3-D model, in order to generate a forcing column for the SCM.

Acknowledgements. Roel Neggers from KNMI is kindly acknowledged for making the KPT system available. We are also grateful to the editor and three reviewers for their comments and constructive suggestions which improved the manuscript considerably.
Edited by: G.-J. Steeneveld

Reviewed by: R. Ronda and two anonymous referees

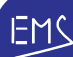

The publication of this article is sponsored by the European Meteorological Society.

\section{References}

de Rooy, W. C. and Siebesma, A. P.: A simple parameterization for detrainment in shallow cumulus, Mon. Weather Rev., 136, 560576, 2008.

de Rooy, W., de Bruijn, C., Tijm, S., Neggers, R., Siebesma, P., and Barkmeijer, J.: Experiences with Harmonie at KNMI, HIRLAM Newsletter, 56, 21-29, 2010.

de Rooy, W. C., Bechtold, P., Fröhlich, K., Hohenegger, C., Jonker, H., Mironov, D., Siebesma, A. P., Teixeira, J., and Yano, J.-I.: Entrainment and detrainment in cumulus convection: an overview, Q. J. Roy. Meteorol. Soc., in press, 2012.

Heus, T., van Heerwaarden, C. C., Jonker, H. J. J., Pier Siebesma, A., Axelsen, S., van den Dries, K., Geoffroy, O., Moene, A. F., Pino, D., de Roode, S. R., and Vilà-Guerau de Arellano, J.: Formulation of the Dutch Atmospheric Large-Eddy Simulation (DALES) and overview of its applications, Geosci. Model Dev., 3, 415-444, doi:10.5194/gmd-3-415-2010, 2010.

Kain, J. S. and Fritsch, J. M.: A one-dimensional entraining/detraining plume model and its application in convective parameterization, J. Atmos. Sci., 47, 2784-2702, 1990.

Neggers, R. A. J., Kohler, M., and Beljaars, A. C. M.: A dual mass flux framework for boundary layer convection. Part I: Transport, J. Atmos. Sci., 66, 1464-1487, 2009.

Neggers, R. A. J., Siebesma, A. P., and Heus, T.: Continuous singlecolumn model evaluation at a permanent observational supersite, B. Am. Meteor. Soc., in press, 2012.

Pergaud, J., Masson, V., Malardel, S., and Couvreux, F.: A parameterization of dry thermals and dry thermals and shallow cumuli for mesoscale numerical weather prediction, Bound.-Lay. Meteorol., 132, 83-106, 2009.

Seity, Y., Brousseau, P., Malardel, S., Hello, G., Benard, P., Bouttier, F., Lac, C., and Masson, V.: The AROME-France ConvectiveScale Operational model, Mon. Weather Rev., 139, 976-991, 2012.

Siebesma, A. P. and Cuijpers, J. W. M.: Evaluation of parametric assumptions for shallow cumulus convection, J. Atmos. Sci., 52, 650-666, 1995.

van Meijgaard, E., van Ulft, L. H., van de Berg, W. J., Bosveld, F. C., van den Hurk, B. J. J. M., Lenderink, G., and Siebesma, A. P.: The KNMI regional atmospheric climate model RACMO, version 2.1. KNMI publication TR-302, 43 pp., 2008. 